J Arid Land (2013) 5(2): 133-142

doi: $10.1007 / \mathrm{s} 40333-013-0153-3$

jal.xjegi.com; www.springer.com/40333

\title{
Lake surface area method to define minimum ecological lake level from level-area-storage curves
}

\author{
SongHao SHANG* \\ State Key Laboratory of Hydroscience and Engineering, Tsinghua University, Beijing 100084, China
}

\begin{abstract}
Lake level assessment is essential for the protection of ecosystem in shrunk or shrinking lakes. Minimum ecological lake level is the critical lake level below which there should be no human activities to further decrease the lake level, and this level can provide a certain protection for the lake ecosystem. Lake surface area method was proposed to define the minimum ecological lake storage as the breakpoint of the lake surface area-storage curve, where the curve slope equals to the ratio of maximum lake surface area to maximum lake storage. If the curve can be expressed as a simple analytical function, the minimum ecological lake storage can be calculated analytically. Otherwise, it can be calculated numerically using the ideal point method for an equivalent multi-objective optimization model that balances ecosystem protection and water use. Then the minimum ecological lake level can be estimated from the lake level-storage curve. Compared with available lake morphology analysis methods, the lake surface area method is superior in its definition of minimum ecological lake level, applicable range of lake morphology, and calculation complexity. The proposed method was applied to two representative lakes in China, including one freshwater lake (the Dongting Lake in Hunan province in Central China) and one saltwater lake (the Ebinur Lake in Xinjiang Uygur autonomous region in Northwest China). The estimated minimum ecological lake level for the Dongting Lake is $26.7 \mathrm{~m}$, at which $31 \%$ of the maximum lake storage provides $87 \%$ of the maximum lake surface area. The result for the Ebinur Lake is $191.2 \mathrm{~m}$, at which $24 \%$ of the maximum lake storage provides $54 \%$ of the maximum lake surface area. The estimated minimum ecological lake level balances the conflict between economical and ecological water uses, and can provide a relatively larger habitat for the lake ecosystem with relatively smaller lake storage. These results are rational compared with the results of other methods. The calculated minimum ecological lake level can be used in the protection of lake ecosystems and the planning and rational use of water resources in lake basins.
\end{abstract}

Keywords: lake level assessment; minimum ecological lake level; lake surface area; lake storage; multi-objective optimization model

Citation: SongHao SHANG. 2013. Lake surface area method to define minimum ecological lake level from level-area-storage curves. Journal of Arid Land, 5(2): 133-142.

With the rapid increase of water diversion from water bodies for domestic, industrial and agricultural uses in recent decades, flow and water level regimes of many rivers, lakes and wetlands have changed significantly, which may have a great impact on ecological water uses of ecosystems dependent on these water bodies.

Lake is an important type of still inland water body that is fed and drained by rivers or streams. The difference between water recharge to and discharge from a lake, as well as the lake morphology, determines the variation of the lake level. Negative balance of lake water due to natural processes and/or human activities leads to the shrinkage or even drying up of a lake (Ma et al., 2010). For example, the Aral Sea in Central Asia, formerly the fourth largest lake in the world with an area of $68,000 \mathrm{~km}^{2}$ in $1960 \mathrm{~s}$, had shrunk dramatically to $10 \%$ of its original size by 2007 due to increasing water diversion from its source rivers

*Corresponding author: SongHao SHANG (E-mail: shangsh@tsinghua.edu.cn) 
(Micklin and Aladin, 2008). The shrinkage or drying up of a large lake can cause serious ecological and environmental disasters (Zhao et al., 2005; Liu et al., 2011). Therefore, it is urgent to assess lake level for the protection of lake ecosystems and environment (Xu et al., 2004; Beca, 2008).

For rivers, over 200 flow assessment methods have been proposed to define a minimum ecological or environmental flow below which no human disturbance should be allowed (Tharme, 2003; Jain, 2012). For lakes, however, only limited lake level assessment methods have been proposed to define a minimum ecological lake level, including historical lake level method, lake morphology analysis, water balance analysis, water quality modeling, habitat analysis, species-environment models, or a combination of the above methods (Xu et al., 2004; Beca, 2008). Similar methods have also been used in the assessment of wetland water level and storage (Li et al., 2009; Tan et al., 2012). However, the relationship between lake level and lake ecosystem has not been fully understood, and most lake level assessment methods consider only part of the factors influencing the lake ecosystem. Moreover, these methods have not been used widely in lake management.

Lake level assessment methods that have been used in practice mainly include the historical lake level method, lake morphology analysis method, habitat analysis method, and species-environment models. The historical lake level method defines minimum ecological lake level as a statistic of the historical lake level records, such as the mean (Beca, 2008) or minimum (Xu et al., 2004) of the annual minimum natural lake level. However, there is no direct connection between historical lake level and lake ecosystem, and the lake ecosystem may degrade severely or keep at a better level at the proposed minimum lake level depending on the fluctuation amplitude of lake level records. The lake morphology analysis defines minimum ecological lake level as the inflection point of the lake level-area curve (Xu et al., 2004), or lake surface area-storage curve (Li et al., 2007). However, inflection points of these curves may not exist for some lakes, and it is still not clear which curve should be used for a specific lake. Both habitat analysis and species-environment models require detailed in situ survey and analysis of the habitat or species-environment interactions (Cui et al., 2005; Abbaspour and Nazaridoust, 2007; Beca, 2008), which restrict their popularization.

In this paper, the lake surface area method was proposed to define minimum ecological lake level from lake level-area-storage curves, with detailed calculation procedures. Then case studies were performed on two representative lakes in China which suffer from shrinkage.

\section{Method}

Minimum ecological lake level is defined as a critical lake level below which there should be no human activities of decreasing the lake level. This level can provide certain protection for the lake ecosystem. Lake surface area and storage corresponding to minimum ecological lake level are called the minimum ecological lake surface area and the minimum ecological lake storage, respectively.

\subsection{Lake surface area method}

In lakes, the biodiversity increases with the surface area (Browne, 1981). Therefore, the lake surface area is an appropriate index for the habitat protection of lake ecosystems. Besides, lake storage is taken as an index for water quantity. Both lake surface area and storage increase with water level. The relationship between lake surface area and storage can be expressed by

$$
S=S(V) .
$$

Where $S$ is the lake surface area, and $V$ is the lake storage.

Generally, lake surface area increases with the storage (Fig. 1a), but the increasing rate or the slope of the $S-V$ curve $(\mathrm{d} S / \mathrm{d} V)$ may increase or decrease with the storage depending on lake morphology. The lake surface area may change rapidly over a certain range of lake storage, and this range can provide more physical habitats for lake ecosystems at a small increase of lake storage. It may also change slowly across the other ranges of lake storage, where the increase of lake storage provides a small increase of physical habitat. Therefore, there may exist a critical lake storage at which the lake surface area changes moderately. 
Similar to the widely used wetted perimeter method (Gippel and Stewardson, 1998) for determining minimum environmental flows for aquatic ecosystems in rivers, the critical lake storage corresponding to the breakpoint of the lake surface area-storage curve (Fig. 1a) can be defined as the minimum ecological lake storage for lake ecosystems. Accordingly, we define this method as the lake surface area method. As shown in Fig. 1a, the lake surface area decreases rapidly below this critical storage, which is apparently unfavorable for the lake ecosystem.

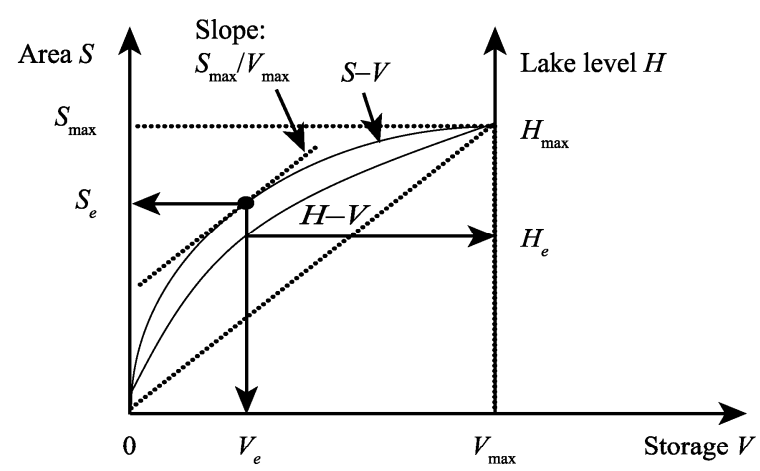

(a) Lake surface area method

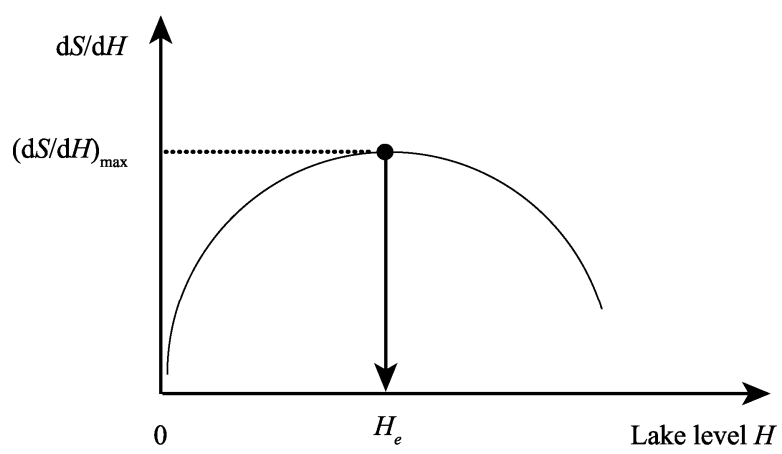

(b) Lake morphology analysis method

Fig. 1 Sketch of the lake surface area method and lake morphology analysis method to estimate minimum ecological lake level $\left(H_{\mathrm{e}}\right)$

To eliminate the scaling effect of lake surface area and storage, dimensionless lake surface area and storage are used instead, which are defined as

$$
\begin{aligned}
& s=S / S_{\max }, \\
& v=V / V_{\max } .
\end{aligned}
$$

Where $s$ and $v$ are dimensionless lake surface area and storage, respectively, and $S_{\max }$ and $V_{\max }$ are maximum lake surface area and lake storage, respectively. Then $s$ can be expressed as a function of $v$, which is

$$
s=s(v) \text {. }
$$

In the wetted perimeter method for determining minimum environmental flow, the breakpoint of wetted perimeter-discharge curve is usually defined as the point where the slope of the curve equals to a critical value (usually 1 for the slope method) or where the curvature of the curve is maximized (the curvature method) (Gippel and Stewardson, 1998). By comparing the slope and curvature methods, the slope method is found to be more appropriate to define the minimum environmental flow (Shang, 2008). Therefore, the slope method is also used here to define the minimum ecological lake storage from the lake surface area-storage curve.

Using the slope method, the dimensionless minimum ecological lake storage $\left(v_{e}\right)$ is determined by the breakpoint of the dimensionless lake surface area-storage curve with the slope equals to a specified value, usually 1 :

$$
\left.\frac{\mathrm{d} s}{\mathrm{~d} v}\right|_{v=v_{e}}=1 .
$$

In this case, at the point of determined $v_{e}$, a small variation in $v$ will result in the same variation in $s$. While for $v>v_{e}$, a larger increase in $v$ only produces a smaller increase in $s$. Other critical values of the curve slope can also be used to reflect the management objectives for the lake, e.g., lower value of the specified slope indicates more consideration for the lake ecosystem.

After the determination of $v_{e}$, minimum ecological lake storage $\left(V_{e}\right)$ can be calculated from

$$
V_{e}=v_{e} \times V_{\max } .
$$

From Eqs. 2, 3 and 5, $V_{e}$ can also be defined directly from

$$
\left.\frac{\mathrm{d} S}{\mathrm{~d} V}\right|_{V=V_{e}}=\frac{S_{\max }}{V_{\max }} .
$$

Therefore, the minimum ecological lake storage is the lake storage at which the slope of the $S-V$ curve $(\mathrm{d} S / \mathrm{d} V)$ equals to the average value of lake surface area per unit storage (the ratio of maximum lake surface area to maximum lake storage, $S_{\max } / V_{\max }$ ). If we 
treat lake storage as the input of water and lake surface area as the output for the ecosystem, the minimum ecological lake storage is the lake storage at which the marginal benefit (increment of output caused by a unit increase of input) equals to the average output per unit input. For lake storage smaller than $V_{e}$, the increase of lake surface area per unit storage is larger than the average value, and vice versa.

Then, minimum ecological lake level $\left(H_{e}\right)$ and minimum ecological lake surface area $\left(S_{e}\right)$ corresponding to $V_{e}$ can be estimated from the lake level $(H)$-area $(S)$-storage $(V)$ curves (Fig. 1a). Furthermore, minimum ecological water requirement of a lake, the amount of water required to maintain the minimum ecological lake level, can also be calculated from lake water balance at the level of $H_{e}$.

Considering the similarity between lake and wetland, the proposed method can also be used to determine minimum ecological water level for wetland.

\subsection{Analytical method to calculate minimum eco- logical lake storage}

The relationship between lake surface area and storage is usually available in scattered data. In some cases, this relationship can be described by simple functions. Then the minimum ecological lake storage can be calculated analytically from Eq. 5 or 7 , and this method is called analytical method.

Lake morphology determines the relationship between lake surface area and storage. For the two representative lakes in China analyzed in Section 2, the results show that the power and logarithmic functions are most suitable to describe their $S-V$ relationships, respectively. As the representative of simple functions, they are taken as examples to illustrate the analytical method to calculate minimum ecological lake storage. For the other types of $S-V$ relationship, the minimum ecological lake storage can be analyzed similarly. The power and logarithmic functions are

$$
\begin{gathered}
S=A V^{B}, \text { or } s=a v^{b} ; \\
S=C \ln V+D, \text { or } s=c \ln v+d .
\end{gathered}
$$

Where $A, a, B, b, C, c, D$, and $d$ are empirical coefficients dependent on the lake morphology, and can be determined from regression analysis of measured $(V, S)$ data. Relationships between these coefficients are

$$
\begin{gathered}
a=A V_{\max }^{B} / S_{\max }, b=B ; \\
c=C / S_{\max }, d=\left(D+C \ln V_{\max }\right) / S_{\max } .
\end{gathered}
$$

Because $s=v=1$ when the lake reaches its highest level, both the regression coefficients $a$ and $d$ should be close to 1 .

The first derivatives of the above power and logarithmic functions are

$$
\begin{gathered}
\frac{\mathrm{d} S}{\mathrm{~d} V}=A B V^{B-1}, \text { or } \frac{\mathrm{d} s}{\mathrm{~d} v}=a b v^{b-1} ; \\
\frac{\mathrm{d} S}{\mathrm{~d} V}=C / V, \text { or } \frac{\mathrm{d} s}{\mathrm{~d} v}=c / v .
\end{gathered}
$$

From Eqs. 5, 7, 12 and 13, the minimum ecological lake storage for the power $\left(V_{e p}\right.$ or $\left.v_{e p}\right)$ and logarithmic $\left(V_{e l}\right.$ or $\left.v_{e l}\right)$ forms of lake surface area-storage curve are

$$
\begin{gathered}
V_{e p}=\left(A B V_{\max } / S_{\max }\right)^{1 /(1-B)}, \quad v_{e p}=(a b)^{1 /(1-b)} ; \\
V_{e l}=C V_{\max } / S_{\max }, \quad v_{e l}=c .
\end{gathered}
$$

Then the minimum ecological lake surface area for the power $\left(S_{e p}\right.$ or $\left.s_{e p}\right)$ and logarithmic $\left(S_{e l}\right.$ or $\left.s_{e l}\right)$ forms of lake surface area-storage curve can be calculated from

$$
\begin{aligned}
& S_{e p}=A\left(A B V_{\max } / S_{\max }\right)^{B /(1-B)}, s_{e p}=a(a b)^{b /(1-b)} ;(16) \\
& S_{e l}=C \ln \left(C V_{\max } / S_{\max }\right)+D, s_{e l}=c \ln c+d .
\end{aligned}
$$

For the power relationship between lake surface area and storage, the dimensionless minimum ecological lake surface area $\left(s_{e p}\right)$ and storage $\left(v_{e p}\right)$ are mainly influenced by the power index $b$ because the coefficient $a$ is close to 1 . By assuming $a=1, v_{e}$ increases with $b$, while $s_{e}$ decreases with $b$ (Fig. 2a).

For the logarithmic relationship between lake surface area and storage, $v_{e}$ equals to the coefficient $c$, and $s_{e}$ is mainly influenced by $c$ because $d$ is close to 1 . By assuming $d=1, s_{e}$ decreases with $c$ for smaller $c$, while increases with $c$ for greater $c$ (Fig. 2b). The minimum value of $s_{e}$ is $1-1 / \mathrm{e}=0.632$ when $c$ is $1 / \mathrm{e}=0.368$. Therefore, the calculated minimum ecological lake surface area will always be greater than $63 \%$ of the maximum area for the logarithmic relationship between lake surface area and storage. 


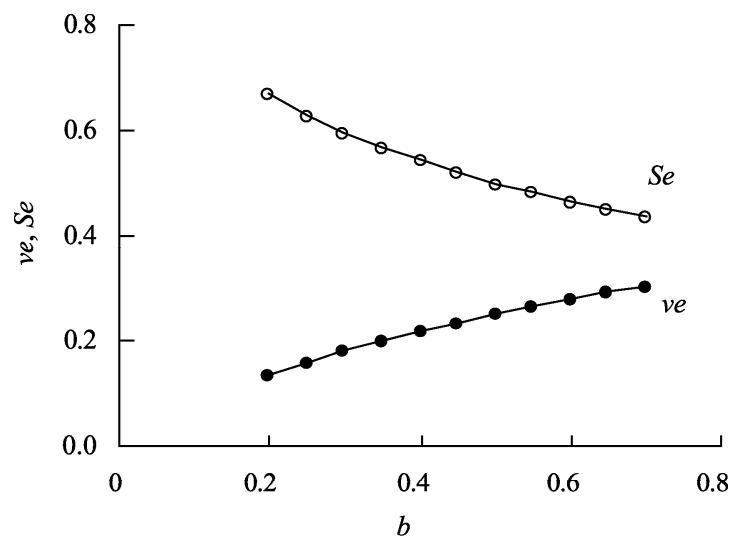

(a) Power function $(a=1)$

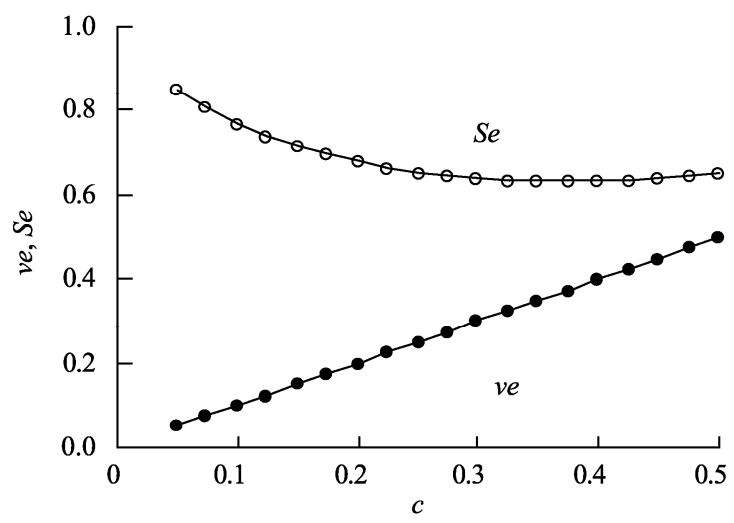

(b) Logarithmic function $(d=1)$

Fig. 2 Minimum ecological lake surface area $\left(s_{e}\right)$ and storage $\left(v_{e}\right)$ for different lake surface area-storage curves

\subsection{Numerical method to calculate minimum ecol- ogical lake storage}

In some other cases, the relationship between lake surface area and storage cannot be expressed as simple functions, and numerical approximation of the first derivative from limited scattered data is error-prone due to measurement errors. Similar to the estimation of minimum environmental flow (Shang, 2008), the minimum ecological lake storage can be estimated from the following multi-objective optimization model using the ideal point method (Shang, 2006):

$$
\left\{\begin{array}{l}
\min z_{1}=v=V / V_{\max }, \\
\max z_{2}=s(v)=S(V) / S_{\max }, \\
\text { s.t. } \quad 0 \leq V \leq V_{\max } .
\end{array}\right.
$$

Where the first objective represents the minimization of lake storage so as to supply more water for economic purposes and to minimize water loss through evaporation and seepage, and the second objective represents the maximization of lake surface area so as to provide more habitats for the lake ecosystem. Therefore, Eq. 18 expresses the balance of ecosystem protection and water requirement to maintain required lake surface area.

The ideal point method with the scaling coefficient of 1 (Shang, 2006) for Eq. 18 (Fig. 3a) results in

$$
\begin{aligned}
& \min d(v)=w_{1} v+w_{2}[1-s(v)]= \\
& w_{1} V / V_{\max }+w_{2}\left[1-S(V) / S_{\max }\right] .
\end{aligned}
$$

Where $d$ is the Manhattan distance between the ideal point $(0,1)$ and a scenario in the objective space $(v$, $s(v))$, and $w_{1}$ and $w_{2}$ are two non-negative weights. For equal weights $\left(w_{1}=w_{2}=1\right)$, Eqs. 5, 7 and 19 are equivalent.

For all available scattered data pairs of $\left(V_{i}, S_{i}\right), i=1$, $2, \ldots, n$, we first need to calculate the distances $d_{i}$ using Eq. 19, then find out the minimum distance $d_{k}=\min \left\{d_{i}, i=1,2, \ldots, n\right\}$ and corresponding lake storage $V_{k}$. The minimum ecological lake storage can be estimated with the parabolic interpolation method for univariate optimization (Fig. 3b) (Shang, 2008), which is

$$
V_{e s}=\frac{1}{2} \frac{d_{k-1}\left(V_{k}^{2}-V_{k+1}^{2}\right)+d_{k}\left(V_{k+1}^{2}-V_{k-1}^{2}\right)+d_{k+1}\left(V_{k-1}^{2}-V_{k}^{2}\right)}{d_{k-1}\left(V_{k}-V_{k+1}\right)+d_{k}\left(V_{k+1}-V_{k-1}\right)+d_{k+1}\left(V_{k-1}-V_{k}\right)}
$$

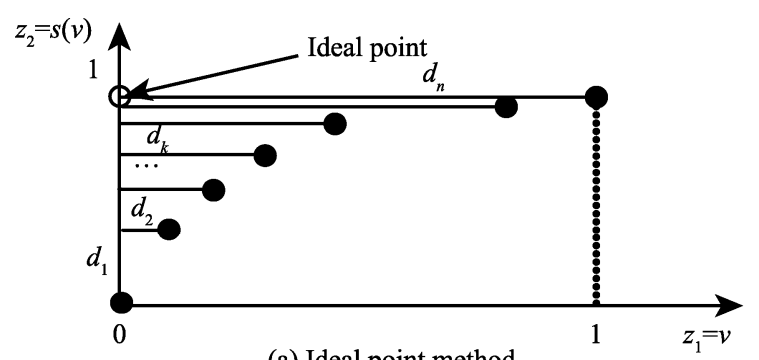

(a) Ideal point method

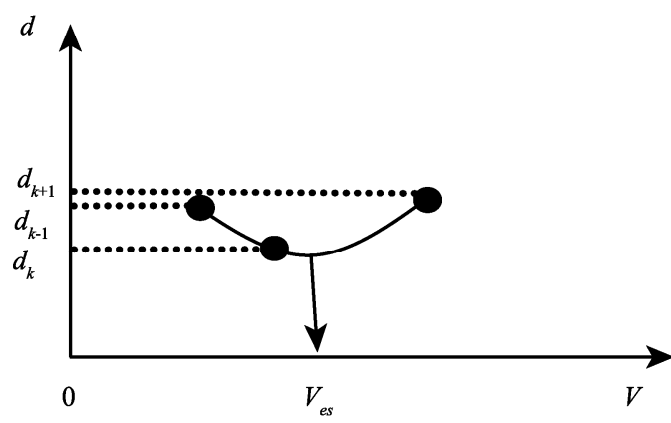

(b) Parabolic interpolation method

Fig. 3 Sketch of the numerical method to calculate minimum ecological lake storage $\left(v_{e s}\right)$ 
Where $V_{e s}$ is minimum ecological lake storage estimated from scattered data pairs of $(V, S)$ using numerical method.

\subsection{Comparison of the lake surface area method and available lake morphology analysis me- thods}

The lake surface area method and available lake morphology analysis methods are all based on lake level-area-storage curves that depend on the morphology of the lake basin. However, they define the minimum ecological lake level in different ways.

Available lake morphology analysis methods usually define the minimum ecological lake level as the inflection point of the lake level-area curve (Xu et al., 2004), at which the variation rate of lake surface area is the highest (Fig. 1b). Below the inflection point, the decreasing rate of lake surface area is large. Therefore, water level at the inflection point is defined as the minimum ecological lake level (Xu et al., 2004). However, the increasing rate of lake surface area is also large when water level is higher than the above defined minimum ecological lake level. It is more appropriate to define the minimum ecological lake level a little higher than that at the inflection point. Some others used the lake surface area-storage curve instead (Li et al., 2007). However, lake surface area is more appropriate to describe the ecological function of a lake than lake storage. Moreover, it is not clear which curve should be used for a specific lake.

Different from available lake morphology analysis methods, the proposed lake surface area method defines the minimum ecological lake storage as the critical storage of the lake surface area-storage curve, where the curve slope equals to a specified value. For dimensionless lake surface area-storage curve, the specified value of curve slope is set to be 1 . While for lake surface area-storage curve, the specified value is set to be the average value of lake surface area per unit storage $\left(S_{\max } / V_{\max }\right)$. In other words, the minimum ecological lake storage is defined by the lake storage at which the marginal lake surface area equals to $S_{\max } / V_{\max }$. For lake storage smaller than the minimum ecological lake storage, the increase of lake surface area per unit storage is larger than the average value, and vice versa. Compared with available lake mor- phology analysis methods, the lake surface area method is more appropriate to define the minimum ecological lake storage.

Moreover, the lake surface area method has some other advantages compared with available lake morphology analysis methods. For available lake morphology analysis methods, the inflection point of the lake level-area curve or lake surface area-storage curve exists only if strict conditions about the curve are met (Editorial Board of Handbook of Mathematics, 1979). For example, there is no inflection point in some simple curves, such as power and logarithmic curves. For the lake surface area method, the minimum ecological lake storage is defined as the critical storage of the lake surface area-storage curve, where the curve slope equals to a specified value. The minimum ecological lake storage defined above requires no inflection point of the curve. Consequently, minimum ecological lake level corresponding to the minimum ecological lake storage can be specified. Therefore, the lake surface area method can be applied to a wider range of lake morphology than available lake morphology analysis methods.

Another advantage of the lake surface area method is that it is simple for computation, because it is unnecessary to estimate the first or second order derivative of the lake surface area-storage curve. In practice, only scattered data of lake surface area-storage are available, while numerical estimation of derivatives from scattered data pairs is both complex and error-prone. In the lake surface area method, the scattered data can be used directly for estimating the minimum ecological lake storage from Eqs. 19 and 20. If the lake surface area-storage curve can be expressed as simple analytical functions, the first derivative of the curve can also be used to estimate the minimum ecological lake storage using Eq. 7. While for available lake morphology analysis methods, the second derivative of the lake level-area curve (Xu et al., 2004) or lake surface area-storage curve (Li et al., 2007) have to be calculated to find the maximum of the curve slope.

\section{Case studies}

The proposed lake surface area method was used to determine the minimum ecological lake level, area, 
and storage for two representative lakes in China, including one freshwater lake (the Dongting Lake) and one saltwater lake (the Ebinur Lake). Table 1 listed the basic information of these two lakes.

\subsection{Dongting Lake}

Dongting Lake, the second largest freshwater lake in China, lies in the north of Hunan province and to the south of Yangtze River. With a drainage area of $25.7 \times 10^{4} \mathrm{~km}^{2}$, the lake is mainly recharged by Xiangjiang, Zishui, Yuanjiang and Lishui rivers as well as four middle Yangtze tributaries. It discharges to the Yangtze River through Chenglingji.

The Dongting Lake and its surrounding wetlands provide suitable habitats for fishes and other aquatic species. During the past several decades, the lake and wetlands have been shrinking due to natural processes and human activities, such as climate change, land reclamation, sedimentary deposition, and water diversion for economical purposes (Jiang and Huang, 2004; $\mathrm{Du}$ et al., 2011). The lake shrinkage has resulted in many ecological and environmental problems, such as the degradation of ecosystems and decrease of fishery resources. Therefore, it is urgent to determine the minimum ecological lake level and water requirement for the Dongting Lake (Xie et al., 2012).

From the water level at Chenglingji Station $(H)$-lake surface area $(S)$-storage $(V)$ curves for the Dongting Lake (Fig. 4a), the relationship between $S$ and $V$ (Fig. 4b) can be described by logarithmic function 9 , and the result of nonlinear regression analysis is

$$
\begin{aligned}
& S=753.3 \ln V-1204.9, \text { or } s=0.314 \ln v-1.15, \\
& R^{2}=0.98, n=12 .
\end{aligned}
$$

Where $R^{2}$ is the coefficient of determination, and $n$ is the number of points used for regression.

Minimum ecological lake storage, area, and water level are determined using the analytical method from Eqs. 15 and 21, and the numerical method from Eqs. 19 and 20. The results of these two methods (Table 2) are very close, and $H_{e}=26.7 \mathrm{~m}$ is chosen as the recommended minimum ecological lake level. At this level, $31 \%$ of the maximum lake storage provides $87 \%$ of the maximum lake surface area.

For Dongting Lake, the minimum ecological lake level was also determined from lake morphology analysis by Xie et al. (2012), where the ratio of lake surface area increment to storage increment reached the peak value. The result was $24.6 \mathrm{~m}$ (Xie et al., 2012), about $2.1 \mathrm{~m}$ lower than that determined using the lake surface area method. Around the lake level with the maximum ratio of lake surface area increment to storage increment, the increase of lake surface area is very significant with a small increase of lake storage. From Fig. 4a, lake surface area increases significantly when the lake level rises from $22.0 \mathrm{~m}$ to $27.0 \mathrm{~m}$. Therefore the present minimum ecological lake level of $26.7 \mathrm{~m}$ is appropriate for the protection of the lake ecosystem. In further studies, ecological and hydrological conditions shall be considered to verify this result.

\subsection{Ebinur Lake}

Ebinur Lake, the largest saltwater lake in Xinjiang, lies in the west of Northern Xinjiang. With a drainage area of $5.06 \times 10^{4} \mathrm{~km}^{2}$, the lake is an endorheic lake mainly recharged by Bortala, Jing and Kuntun rivers.

The Ebinur Lake lies in an extremely arid region, where the annual precipitation (about $100 \mathrm{~mm}$ ) is far less than water surface evaporation (over 1,500 mm). The lake water is the base for lake ecosystems and surrounding wetland ecosystems that are important for local environment. During the 1950s-1970s, the lake shrank rapidly from $1,200 \mathrm{~km}^{2}$ to $500 \mathrm{~km}^{2}$, which was mainly caused by water diversion from its source rivers. During the 1980s, the lake surface area remained at a lower level. In the recent twenty years, the lake surface area fluctuated with climate. The shrinkage of the lake had led to severe ecological and environmental disasters, such as ecosystem degradation,

Table 1 Basic information of the two representative lakes

\begin{tabular}{ccccccc}
\hline No. & Lake & Location & Latitude and longitude & $H_{\max }{ }^{\mathrm{a}}(\mathrm{m})$ & $S_{\max }\left(\mathrm{km}^{2}\right)$ & $V_{\max }\left(10^{8} \mathrm{~m}^{3}\right)$ \\
\hline 1 & Dongting $^{\mathrm{b}}$ & Hunan province & $28^{\circ} 44^{\prime}-29^{\circ} 35^{\prime} \mathrm{N}, 111^{\circ} 53^{\prime}-113^{\circ} 05^{\prime} \mathrm{E}$ & 33.0 & 2395.6 & 192.9 \\
2 & Ebinur $^{\mathrm{c}}$ & Xinjiang Uygur autonomous region & $44^{\circ} 34^{\prime}-45^{\circ} 08^{\prime} \mathrm{N}, 82^{\circ} 35^{\prime}-83^{\circ} 16^{\prime} \mathrm{E}$ & 195.0 & 1051.4 & 33.9 \\
\hline
\end{tabular}

Note: a, $H_{\max }$ refers to the higher lake level in natural state; b, Data from Jiang and Huang (2004); c, Data from Liu et al. (2008). 


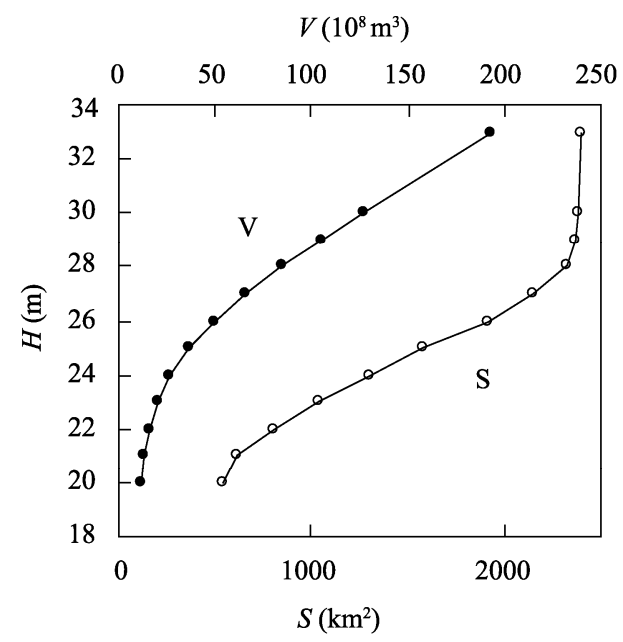

(a) $H-S$ and $H-V$ curves (Jiang and Huang, 2004)

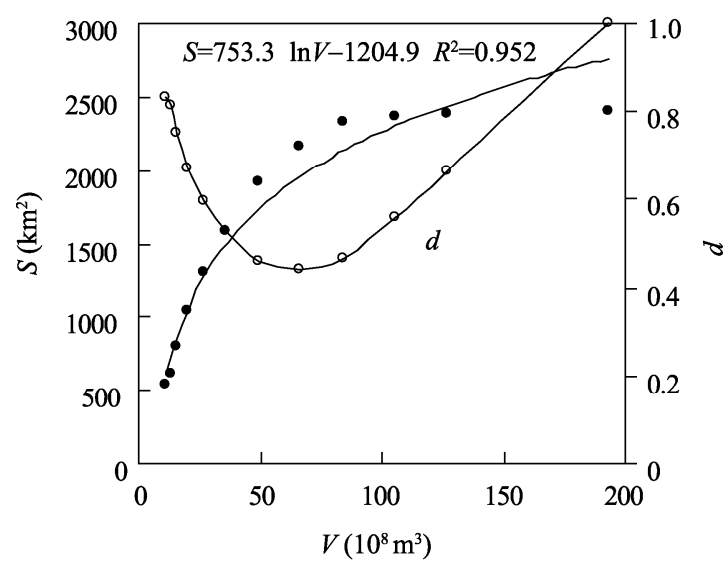

(b) $S-V$ and $d-V$ curves

Fig. 4 Relationship between water level at Chenglingji Station $(H)$, lake surface area $(S)$ and storage $(V)$ and calculated Manhattan distance $(d)$ for the Dongting Lake

desertification, and sandstorms (Liu et al., 2011). Therefore, it is necessary to study the minimum ecological lake level for the protection of ecology and environment.

From the lake level $(H)$-lake surface area
$(S)$-storage $(V)$ curves for the Ebinur Lake (Fig. 5a), the relationship between $S$ and $V$ (Fig. $5 b$ ) can be described by power function 10 as follows

$$
\begin{aligned}
& S=187.5 V^{0.496} \text { or } s=1.024 v^{0.496}, \\
& R^{2}=0.98, \quad n=8 .
\end{aligned}
$$

Minimum ecological lake storage, area and level are determined using the analytical method from Eqs. 14 and 22, and the numerical method from Eqs. 19 and 20. Results of these two methods (Table 2) are very close. Considering the minor difference of lake surface area between these two methods, $H_{e}=191.2 \mathrm{~m}$ is chosen as the recommended minimum ecological lake level. At this level, $24 \%$ of the maximum lake storage provides $54 \%$ of the maximum lake surface area.

Liu et al. (2008) also studied the minimum ecological lake level of the Ebinur Lake using historical lake level analysis, lake morphology analysis, habitat analysis methods, and the integration of all the above. In the historical lake level analysis method, $192.2 \mathrm{~m}$, the minimum lake level from 2002 to 2006, was taken as the minimum ecological lake level. However, this lake level is significantly higher than the historical minimum lake level of $190.0 \mathrm{~m}$. As shown in Fig. 5a, lake surface area increases rapidly for lake level increasing from 190.0 to $191.0 \mathrm{~m}$, while much more slowly from 191.0 to $192.0 \mathrm{~m}$. Therefore, Liu et al. (2008) took $191.0 \mathrm{~m}$ as the minimum ecological lake level from lake morphology analysis. In the lake, phytoplankton and mollusk are abundant, among which brine shrimp (Artemia salina) is the most important biological resource. Brine shrimp grows mainly in areas with water depth over $2.9 \mathrm{~m}$. Therefore, Liu et al. (2008) took $190.9 \mathrm{~m}$ as the minimum ecological lake level, considering the requirement of brine shrimp growth. Consequently, the minimum ecological lake level was determined to be $191.4 \mathrm{~m}$ by the integration of the above results (Liu et al., 2008). Our result from

Table 2 Minimum ecological lake storage $\left(V_{e}\right)$, area $\left(S_{e}\right)$, and level $\left(H_{e}\right)$ for two representative lakes

\begin{tabular}{clrrrrr}
\hline Lake & Method & $V_{e}\left(10^{8} \mathrm{~m}^{3}\right)$ & $v_{e}(\%)$ & $S_{e}\left(\mathrm{~km}^{2}\right)$ & \multicolumn{1}{c}{$s_{e}(\%)$} & $H_{e}(\mathrm{~m})$ \\
\hline \multirow{3}{*}{ Dongting } & Analytical & 60.7 & 31.4 & 2,077 & 86.7 & 26.7 \\
& Numerical & 64.7 & 33.5 & 2,135 & 89.1 & 26.9 \\
& Difference & 4.0 & 2.1 & 58 & 2.4 & 0.2 \\
& Analytical & 8.85 & 26.1 & 573 & 54.5 & 191.3 \\
& Numerical & 8.06 & 23.8 & 571 & 54.3 & 191.2 \\
& Difference & -0.79 & -2.3 & -2 & -0.2 & -0.1 \\
\hline
\end{tabular}




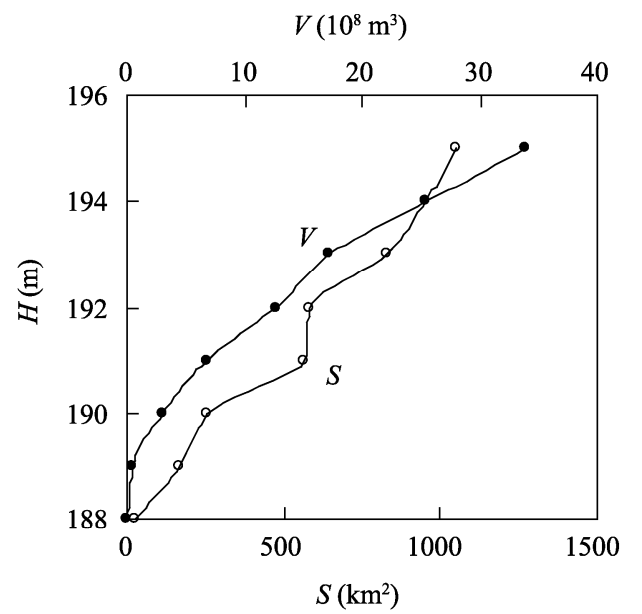

(a) $H-S$ and $H-V$ curves (Liu et al., 2008)

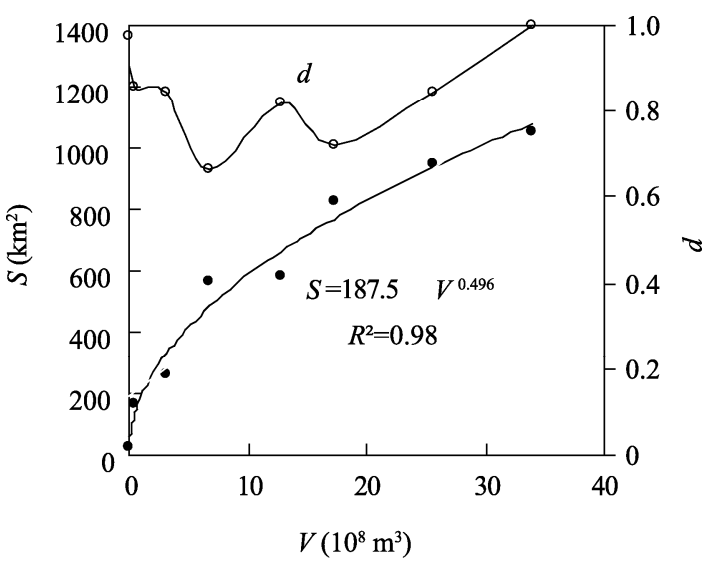

(b) $S-V$ and $d-V$ curves

Fig. 5 Relationship between water level $(H)$, surface area $(S)$ and storage $(V)$ and calculated Manhattan distance $(d)$ for the Ebinur Lake

the proposed lake surface area method is $191.2 \mathrm{~m}$, which is slightly higher than the values from lake morphology analysis and habitat analysis and slightly lower than the integrated value. At the lake level of $191.2 \mathrm{~m}$, the lake can provide essential habitat for the most important biological resource, and benefit the protection of wetlands around the Ebinur Lake (Liu et al., 2008) and the control of wind erosion from dried-up lake bed to some extent (Liu et al., 2011).

\section{Discussion}

The lake surface area method was used to determine minimum ecological lake level for two representative lakes in China. Comparisons of the minimum ecological lake level estimated from the lake surface area method and other methods (Liu et al., 2008; Xie et al.,
2012) indicate that the proposed method is applicable to determine the minimum ecological lake level for both lakes.

These two representative lakes include one freshwater lake (the Dongting Lake) and one saltwater lake (the Ebinur Lake). Ecosystems in freshwater lakes and saltwater lakes have different characteristics, and their demands for water quality and quantity are also different. However, they all require certain lake level and area to provide suitable habitat. To maintain a suitable ecological level in the lake, water consumed through evaporation and seepage should be recharged by inflows and precipitation. Water consumption or recharge may be a better index for water volume, but they are available only when the lake water balance is fully understood (Beca, 2008). Considering that water consumption is closely related with lake level or storage, lake storage can be taken as an alternative index for water volume. The relationship between lake surface area and storage is the base for the proposed lake area method, which relies on the lake morphology or the characteristics of the lake. The starting point of this method is to provide more habitats for lake ecosystems with less water, which express the tradeoff between economical water use and lake ecosystem protection in both freshwater lakes and saltwater lakes in cases of water shortage. A similar method has been used to determine the ecological flow of rivers by Shang (2008). Therefore, the proposed method is applicable to both freshwater lakes and saltwater lakes, as can be seen from the two representative lakes. Of course, more case studies are required to testify and improve the proposed method in future research.

\section{Conclusions}

To protect lake ecosystems in shrinking lakes, our study proposed the lake surface area method to define the minimum ecological lake storage as the breakpoint of the lake surface area-storage curve, where the curve slope equals to the ratio of maximum area to maximum storage. Two ways of calculation were explored, namely analytical and numerical methods. If the lake surface area-storage curve can be expressed as a power, logarithmic or other simple analytical functions, the minimum ecological lake storage can be calculated analytically. Otherwise, it can be calculated 
numerically from scattered data pairs of lake surface area and storage by the ideal point method for an equivalent multi-objective optimization model that balances ecosystem protection and water requirement. Then corresponding minimum ecological lake level and area can be estimated from the lake level-area-storage curves. From comparison of the proposed lake surface area method and available lake morphology analysis methods that define minimum ecological lake level as the inflection point of the lake level-area curve, the former is superior in its definition of minimum ecological lake level, applicable range of lake morphology, and calculation complexity.

The proposed lake surface area method was used to calculate minimum ecological lake level for two representative lakes in China. The minimum ecological lake level of the Dongting Lake and the Ebinur Lake are 26.7 and $191.2 \mathrm{~m}$, respectively, which are rational compared with the results of other methods. Estimated minimum ecological lake level balances the conflict between economical and ecological water uses, and can provide relative larger habitat for the lake ecosystem with relative smaller lake storage. It can be further used to calculate the minimum ecological water requirement that is required to maintain the minimum ecological lake level, which is useful in the protection of the lake ecosystem and the planning and rational use of water resources in a lake basin.

\section{Acknowledgements}

This work was funded by the National Natural Science Foundation of China (50879041).

\section{References}

Abbaspour M, Nazaridoust A. 2007. Determination of environmental water requirements of Lake Urmia, Iran: an ecological approach. International Journal of Environmental Studies, 64(2): $161-169$

Beca. 2008. Draft Guidelines for the Selection of Methods to Determine Ecological Flows and Water Levels. Report prepared by Beca Infrastructure Ltd for MfE. Wellington: Ministry for the Environment, 41-73.

Browne R A. 1981. Lakes as islands: biogeographic distribution, turnover rates, and species composition in the lakes of central New York. Journal of Biogeography, 8(1): 75-83.

Cui B S, Zhao X, Yang Z F. 2005. Eco-hydrology-based calculation of the minimum ecological water requirement for lakes. Acta Ecolo- gica Sinica, 25(7): 1788-1795.

Du Y, Xue H P, Wu S J, et al. 2011. Lake area changes in the middle Yangtze region of China over the $20^{\text {th }}$ century. Journal of Environmental Management, 92(4): 1248-1255.

Editorial Board of Handbook of Mathematics. 1979. Handbook of Mathematics. Beijing: Higher Education Press, 238.

Gippel C J, Stewardson M J. 1998. Use of wetted perimeter in defining minimum environmental flows. Regulated Rivers: Research \& Management, 14(1): 53-67.

Jain S K. 2012. Assessment of environmental flow requirements. Hydrological Processes, 26(22): 3472-3476.

Jiang J H, Huang Q. 2004. Analysis of the lake basin change and the rushing-silting features in the past decades of Dongting Lake. Journal of Lake Sciences, 16(3): 209-214.

Li L J, Li J Y, Liang L Q, et al. 2009. Method for calculating ecological water storage and ecological water requirement of marsh. Journal of Geographical Sciences, 19(4): 427-436.

Li X H, Song Y D, Li Y T, et al. 2007. Calculation methods of lowest ecological water level of lake. Arid Land Geography, 30(4): 526-530.

Liu D W, Abuduwaili J, Lei J Q, et al. 2011. Wind erosion of saline playa sediments and its ecological effects in Ebinur Lake, Xinjiang, China. Environmental Earth Sciences, 63(2): 241-250.

Liu Y Q, Wang X F, Wu Y. 2008. Study on the lowest ecological water level of Aiby Lake. Journal of Arid Land Resources and Environment, 22(10): 111-114.

Ma R H, Duan H T, Hu C M, et al. 2010. A half-century of changes in China's lakes: Global warming or human influence? Geophysical Research Letters, 37, L24106, doi: 10.1029/2010GL045514.

Micklin P, Aladin N V. 2008. Reclaiming the Aral Sea. Scientific American, 298(4): 64-71.

Shang S H. 2006. System Analysis of Water Resources: Methods and Applications. Beijing: Tsinghua University Press, 135-137.

Shang S H. 2008. A multiple criteria decision-making approach to estimate minimum environmental flows based on wetted perimeter. River Research and Applications, 24(1): 54-67.

Tan Y Y, Wang X, Li C H, et al. 2012. Estimation of ecological flow requirement in Zoige Alpine Wetland of southwest China. Environmental Earth Sciences, 66(5): 1525-1533.

Tharme R E. 2003. A global perspective on environmental flow assessment: Emerging trends in the development and application of environmental flow methodologies for rivers. River Research and Applications, 19(5-6): 397-441.

Xie Y H, Li F, Chen X S. 2012. Study on the minimum ecological water demand for the Dongting Lake. Resources and Environment in the Yangtze Basin, 21(1): 64-70.

$\mathrm{Xu}$ Z X, Chen M J, Dong Z C. 2004. Researches on the calculation methods of the lowest ecological water level of lake. Acta Ecologica Sinica, 24(10): 2324-2328.

Zhao S Q, Fang J Y, Miao S L, et al. 2005. The 7-decade degradation of a large freshwater lake in central Yangtze River, China. Environmental Science and Technology, 39(2): 431-436. 